Вестник ВГУ. Серия: Право

УДК 341.1/8

DOI https://doi.org/10.17308/vsu.proc.law.2020.2/2817

\title{
О РОЛИ ПРИНЦИПОВ ПРАВА ЕВРОПЕЙСКОГО СОЮЗА В ЕГО ВЗАИМОДЕЙСТВИИ С НАЦИОНАЛЬНЫМ ПРАВОМ ГОСУДАРСТВ-ЧЛЕНОВ
}

\author{
Д. В. Галушко \\ Воронежский государственный университет \\ Поступила в редакцию 25 февраля 2020 г.
}

\begin{abstract}
Аннотация: дается характеристика правовой систель Европейского союза как автонолного образования, что проявляется в механизме реализаиии его норм в правовых систелах государств-членов. Особенности процесса илплелентации колмунитарных норл обусловлены принципали права $E C$, прежде всего приниипом верховенства и прялого действия. В связи с отсутствиел в первичнол праве ЕС четкого механизла взаилодействия колмунитарного права с национальныл правол автором проанализирована соответствующая практика Суда EC, которая во многол восполняет указанные пробельь. Учитыьая, что государства-члены обязаны создать необходилье условия для илплелентации норл права ЕС в национальных правопорядках, были также рассмотрены отдельные черты данного процесса. Ключевые слова: Европейский союз, право ЕC, приниип верховенства, принцип прямого действия, принцип субсидиарности, принцип пропорииональности, принцип наделения полнолочияли, принцип лояльности, илплелентация, механизм илплементации.
\end{abstract}

\begin{abstract}
European Union as an autonomous entity, which is manifested in the mechanism for the implementation of its norms in the legal systems of member states. The particularities of the process of implementation of communitarian norms are determined by the principles of EU law, primarily the principle of supremacy and direct effect. Due to the absence in EU primary law of a clear mechanism for the interaction of communitarian law with national law, the author analyzes the relevant practice of the EU Court of Justice, which largely fills these gaps. Given that member states are obliged to create necessary conditions for implementation of EU law in national legal orders, certain features of this process were also considered.

Key words: European Union, EU law, principle of supremacy, principle of di-

284 rect effect, principle of subsidiarity, principle of proportionality, principle of conferral, principle of loyalty, implementation, mechanism of implementation.
\end{abstract}

Право Европейского союза стало результатом взаимодействия различных правовых режимов и межгосударственных отношений, вобрав в себя достижения и правовые традиции европейских государств ${ }^{1}$. В праве ЕС отразились единство многообразия правовых культур, фрункциональность согласования правовых норм объединения с национальными пра-

${ }^{1}$ Cм.: Koopmans T. The Birth of European Law at the CrossRoads of Legal Traditions // The American Journal of Comparative Law. 1991. 39(3). P. 493.

(C) Галушко Д. В., 2020 


\section{Международное и европейское право}

вовыми особенностями государств-членов ${ }^{2}$. Право ЕС, пройдя проверку временем и став эффрективным регулятором общественных отношений в межгосударственном объединении наряду с уважением к национальным правовым системам, одновременно оказалось мощным интегратором многочисленных новаций в национальные правопорядки. В настоящее время правовая система ЕС, созданная и функционирующая на основе международного права, является особым автономным образованием, определяющей основой деятельности которого является достижение целей и задач в различных сфрерах его компетенции ${ }^{3}$.

Неразрывную связь с правовыми системами государств-членов обусловливают принципы функционирования правовой системы Европейского союза, тем самым определяя компетенцию и особенности формирования его институциональной системы, которая, будучи построенной на основе учета особенностей наднационального и межправительственного сотрудничества, служит достижению целей, поставленных перед Европейским союзом. Именно они являются определяющими в процессе развития права ЕС, определяя направления правоприменительной и правотворческой деятельности в рамках данной организации.

Автономный характер права $\mathrm{EC}$ находит свое отражение в механизме реализации его норм во внутренних правопорядках государств-членов. Для него характерно верховенство права ЕС над внутренним правом государств-членов и прямое действие норм права ЕС на территории государств-членов ${ }^{4}$.

В договорах о создании Европейских сообществ не закреплялось четкого механизма взаимодействия коммунитарного права с национальным правом, а дальнейшее сотрудничество нуждалось в решении данной проблемы. Во многом решил эту дилемму Суд ЕС 15 июля 1964 г. по делу Flaminio Costa v E.N.E.L. ${ }^{5}$, введя принцип верховенства права Европейских сообществ и став концептуальным для развития европейского интеграционного правопорядка. В данном деле истец являлся акционером энергетической компании, которая была национализирована в соответствии с итальянским законодательством. Г-н Коста в обоснование своих требований утверждал, что соответствующее итальянское законодательство противоречит положениям Договора о Европейском сообществе 1957 г. В результате рассмотрения дела Суд признал, что, несмотря на то что закон о национализации был принят после ратификации Италией учредительного Договора EC, принцип «Lex posterior derogat priori» ${ }^{6}$

\footnotetext{
${ }^{2}$ Cм.: Craig P. P., De Búrca G. The evolution of EU law. Oxford: Oxford University Press, 2011. P. 324.

${ }^{3}$ Cm.: Law of the European Union: a Textbook for Master Students / ed. by P. Biriukov and V. Tuliakov. Voronezh: VSU Publishing House, 2016. P. 78.

${ }^{4}$ См.: Интеграционное право в современном мире : сравнительно-правовое исследование / С. Ю. Кошкин [и др.]. М., 2015. С. 85.

${ }_{5}^{5}$ Flaminio Costa v E.N.E.L. - Reference for a preliminary ruling: Giudice conciliatore di Milano - Italy. Case 6/64. [1964] ECR 585.

${ }^{6}$ Лат. «Последующий закон отменяет предыдущий».
} 


\section{Вестник ВГУ. Серия: Право}

к рассматриваемому делу не применяется, т. е. национальное право ни при каких обстоятельствах не может иметь приоритета перед правом Сообщества, поскольку иначе все право Сообщества не имело бы смысла7

Суд ЕС утвердил в указанном решении принцип верховенства права Сообщества над национальным правом, легализовав такой подход (включая, среди прочего, аргументы относительно автономного правового порядка, созданного Договором об учреждении Европейского экономического сообщества, ограничения компетенции стран-участниц, угроз для реализации интеграционных задач). Судебным решением государствам-членам было запрещено принимать новые нормативные акты, которые противоречили бы предписаниям Договора об учреждении Европейского экономического сообщества и создавали бы тем самым коллизионные прецеденты ${ }^{8}$.

Решение по делу Costa является одним из самых «знаковых решений» Суда $\mathrm{EC}^{9}$ и иллюстрирует сложный характер права Европейского союза и его связь с национальным правом государств-членов ${ }^{10}$. Из решения следует, что государства-члены согласились утратить часть своих государственных полномочий, поскольку они согласились передать реализацию некоторых из них наднациональному объединению, это означает, что ЕС имеет свои собственные режимы правового регулирования.

Последующие решения Суда ЕС были направлены на расширение сферы верховенства коммунитарного права. Было постановлено, что правовая природа Сообществ исключает «соответствующее принятие новых национальных норм в той части, в которой они были бы несовместимы с положениями права Европейских сообществ. Суд также указал, что в случае коллизии между правом Сообществ и национальными нормами, последние могут не учитываться ${ }^{11}$.

Решение Суда ЕС от 9 марта 1978 г. по делу Simmenthal SpA разви이 вало содержание принципа верховенства права Европейских сообществ. Отмечалось, что «в соответствии с принципом приоритета права Сообщества соотношение между предписаниями учредительного договора и актами институтов, которые подлежат непосредственному применению,

$286{ }^{7}$ Cм.: Loth W. Building Europe: A History of European Unification. Berlin: DE GRUYTER, 2015. P. 119.

${ }^{8}$ Cм.: Ravluševiius P. The Enforcement of the Primacy of the European Union Law: Legal Doctrine and Practice // Jurisprudence. 2011. 18(4). P. 1376.

${ }^{9}$ Cm.: Mangold A. Costa v ENEL (1964) On the Importance of Contemporary Legal History // Inter-Trans-Supra? Legal Relations and Power Structures in History. Proceedings of the 15th European Forum of Young Legal Historians, Florence, (Jahrbuch junge Rechtsgeschichte / Yearbook of Young Legal History). Saarbrücken: AV Akademikerverlag, 2011. P. 220.

10 Flaminio Costa v E.N.E.L. Reference for a preliminary ruling: Giudice conciliatore di Milano - Italy. Case 6/64. [1964] ECR 585. Paras. 3 and 7.

${ }^{11}$ См.: Марченко М. Н. Верховенство права Европейского союза по отношению к национальному праву государств-членов // Журнал рос. права. 2009. № 5 (149). C. 122 . 


\section{Международное и европейское право}

с одной стороны, и национальным правом, с другой стороны, является таковым, что с момента вступления в силу данных положений они не только автоматически делают не подлежащей применению любую действующую норму национального права, которая им противоречит, но и препятствуют законному принятию новых национальных законодательных актов настолько, насколько они будут несовместимыми с предписаниями Сообщества» ${ }^{12}$. Тем самым государства-члены были обязаны избегать принятия новых национальных нормативно-правовых актов, которые порождали бы коллизию и противоречили бы законодательству ЕС.

В деле Simmenthal SpA Суд EC указывал, что несоответствие национальной нормы праву Сообщества не влечет ее автоматического аннулирования. Обязанность отказа в применении противоречащей нормы национального законодательства была возложена на суд, рассматривающий конкретное дело. Суд ЕС признает принцип верховенства европейского права в отношении его применения, а не действительности и законности, в связи с чем национальная норма, которая противоречит праву Сообщества, не теряет силу, но и не может быть применена. На практике действие принципа верховенства права ЕС состоит в том, что любой национальный судебный орган или иной орган государственной власти должен по собственной инициативе учитывать этот приоритет и игнорировать противостоящее национальное право ${ }^{13}$.

В случае коллизии национальных правовых норм с положениями права ЕС последнее имеет преимущественную силу при условии, что общественные отношения подпадают под действие норм Союза ${ }^{14}$. Соответственно, в случае коллизии между национальной нормой и нормой ЕС первая должна быть отменена, независимо от ее места в национальном правопорядке и времени принятия. Судебная практика ЕС наглядно демонстрирует, что коллизии между законодательством ЕС и нормами национального права возможны и практически неизбежны ${ }^{15}$.

Верховенство права ЕС также означает, что обязанность национальных правоприменительных органов состоит в обеспечении әффеективной правовой защиты лицу от действия национального права, противоречащего коммунитарному праву. В данном отношении принцип эффеективного применения права Сообществ предусматривает также обеспечение необходимой временной правовой защиты, даже если это связано с неприменением национального законодательного акта, если он противоречит праву ЕС. Такая позиция Суда вытекает из обязанности лояльного сотрудничества государств-членов в процессе реализации права ЕС.

${ }_{12}$ Amministrazione dell Finanze dello Stato v Simmenthal SpA. Case 106/77. [1978] ECR 629.

${ }^{13}$ См.: Петерс А. Правовые системы и процесс конституционализации : новое определение соотношения // Дайджест публичного права. 2013. Вып. 2. С. 302.

${ }^{14}$ Cм.: Case C-260/89, Elliniki Radiophonia Tileorassi Anonimi Etairia (ERT AE). [1991] ECR I-2951.

${ }^{15}$ Cm.: Goldoni M. Constitutional Pluralism and the Question of the European Common Good // European Law Journal. 2012. Vol. 18, Iss. 3. P. 396. 


\section{Вестник ВГУ. Серия: Право}

Говоря о принципе верховенства права Сообщества над национальным правом государств-членов, следует понимать, что со вступлением в силу Лиссабонского договора этот принцип начал применяться к праву Союза. Кроме того, важно отметить, что все государства-члены при разработке Лиссабонского договора подписали Декларацию № 17 о верховенстве $^{16}$, в которой закрепили принцип верховенства права ЕС над правом государств-членов. Хотя декларация не имеет обязательной силы, тем не менее, принцип верховенства закреплен в ней именно в таком виде, как был определен Судом ЕС в своей практике.

Важное значение во взаимодействии национального права государств-членов с правом ЕС также отводится принципу прямого действия. Принцип прямого действия права ЕС закреплен решением Суда ЕС по делу Van Gend \& Loos от 5 февраля 1963 г. $^{17}$, которое даже называют элементом «правовой революции» в $\mathrm{EC}^{18}$. Суд $\mathrm{EC}$ подчеркнул, что «Сообщество создало новый правопорядок международного права, в пользу которого государства ограничили свои суверенные права, хотя и в отдельных сферах, и к кругу субъектов которого относятся не только государства-члены, но также и их граждане. Право Сообщества независимо от законодательства государств-членов не только возлагает обязанности на частные лица, но также наделяет их правами, которые становятся частью их правового наследия» ${ }^{19}$.

В теоретическом и практическом планах принцип прямого действия права ЕС проявляется в виде возможности и способности норм, содержащихся в актах, которые изданы органами и институтами Союза, выступать в виде регулятора общественных отношений, возникающих на территории стран-членов, непосредственно, напрямую, без необходимости каких-либо форм их официального признания со стороны государств ${ }^{20}$.

$\sim \quad$ К особенностям этого принципа относится и разделение его действия 을 «а «горизонтальное» и «вертикальное». Под «вертикальным» действием понимают отношения между индивидом и государством, а под «горизонтальным» - отношения между физическими и юридическими лицами. Суть принципа прямого действия сводится также к тому, что право ЕС

$288{ }^{16}$ Declaration concerning primacy. URL: https://eur-lex.europa.eu/legal-content/EN/TXT/?uri=CELEX\%3A12008E\%2FAFI\%2FDCL\%2F17 (дата обращения: 10.02.2020).

${ }^{17}$ NV Algemene Transport- en Expeditie Onderneming van Gend \& Loos V Netherlands Inland Revenue Administration. Reference for a preliminary ruling: Tariefcommissie - Netherlands. Case 26-62. [1963] ECR 1.

${ }^{18}$ Cm.: Van Leeuwen K. Paving the road to 'legal revolution': The Dutch origins of the first preliminary references in European law (1957-1963) // European Law Journal. 2018. Vol. 24, Issue 6. P. 408-421.

${ }_{19}$ NV Algemene Transport- en Expeditie Onderneming van Gend \& Loos v Netherlands Inland Revenue Administration. Reference for a preliminary ruling: Tariefcommissie - Netherlands. Case 26-62. [1963] ECR 1.

${ }^{20}$ См.: Марченко М. Н., Дерябина Е. М. Право Европейского союза. Вопросы истории и теории. М., 2010. С. 388. 


\section{Международное и европейское право}

касается каждого, независимо от того, идет ли речь о государстве-члене, или о его гражданах. Правовые акты ЕС обязательно и непосредственно применяют властные национальные органы и суды независимо от согласия и условий, которые устанавливают государства-члены. Практика Суда ЕС основывается на прямом действии, предоставляющем юридическим и фризическим лицам права, которые должны защищать национальные суды ${ }^{21}$.

В отличие от участия государств в международных организациях, членство в Союзе ведет к ограничению государствами-членами своих суверенных прав, реализацию части которых они передают ЕС. Полномочия, переданные со стороны государств-членов, были закреплены в учредительных договорах Союза, которые определяют пределы компетенции Союза, иными словами, принцип наделения полномочиями и средства ее реализации, а именно: принципы субсидиарности и пропорциональности, согласно ст. 5 Договора о Европейском союзе ${ }^{22}$.

Принцип наделения полномочиями означает, что ЕС имеет полномочия только в пределах своей компетенции, которую предоставили ему в Договорах государства-члены для достижения этих целей, установленных Договорами. Согласно п. 2 ст. 5 Договора о ЕС, границы полномочий EC должны уважать как органы Союза, так и государства-члены, и они должны быть соблюдены как во внешней, так и во внутренней деятельности Сообщества ${ }^{23}$.

Особый характер права ЕС предусматривает фрункционирование соответствующих механизмов реализации и действия его норм на уровне Союза и государств-членов. Механизм реализации права ЕС представляет собой совокупность мероприятий с целью обеспечения действия права $\mathrm{EC}$ в государствах-членах. Способы и объем регулирования определяют как ЕС, так и государства-члены в зависимости от имеющейся компетенции. Со своей стороны государства-члены создают для реализации актов ЕС на своей территории соответствующие правовые условия. Каждое государство - член ЕС должно адаптировать свое законодательство для надлежащего выполнения своих обязательств, вытекающих из членства в данном региональном интеграционном образовании. Тем самым вносятся изменения в национальные конституции и законодательство, регулирующее общественные отношения в сферах, правомочия в которых передаются в ведение $\mathrm{EC}^{24}$.

Поскольку принцип прямого действия по-разному распространяет свое действие на различные источники права ЕС, Суд ЕС выработал

\footnotetext{
${ }^{21}$ Cm.: Pastushok A. Principles of Community Law: Philosophic and Legal Analysis // European Researcher. 2012. Vol. 37, № 12-2. P. 2226.

22 Договор о Европейском Союзе. URL: https://eulaw.ru/treaties/teu/ (дата обращения: 01.02.2020).

${ }^{23}$ См., например: Commission of the European Communities v Council of the European Communities (ERTA). Case 22/70. [1971] ECR I 263.

${ }^{24}$ См.: Мансурова Ж. Т. Условия членства и процедура принятия новых государств в Европейском союзе : автореф. дис. ... канд. юрид. наук. М., 2003. С. 2.
} 


\section{Вестник ВГУ. Серия: Право}

принцип толкования национального законодательства в максимально возможной степени в соответствии с законодательством $\mathrm{EC}^{25}$. По существу, этот принцип подразумевает, что положения внутреннего законодательства государств - членов Союза должны истолковываться национальными органами в соответствии с положениями права ЕC.

Суд ЕС своими решениями унифицировал также подход к введению положений права ЕС во внутренние правопорядки государств-членов. В своем решении по делу San Michele Spa он отметил, что рецепция не имеет своим результатом их трансформацию во внутреннее право, и поэтому они должны применяться национальными судами не как внутреннее право, а как право $\mathrm{EC}^{26}$. Впоследствии эта позиция Суда ЕС была признана национальными судами. Более того, страны, которые присоединялись к ЕС в последующие годы, учли необходимость обеспечения таких условий реализации норм права ЕС на своей территории, которые исходили бы из признания автономного характера правопорядка Европейского союза, который носит основополагающий характер для государств-членов и имеет приоритет перед национальным правом только в тех сферах, в которых Союзу были переданы государственные полномочия ${ }^{27}$.

В связи с тем что реализация права ЕС осуществляется в основном на территории государств-членов, они обязаны создать соответствующие условия для данного процесса. Национальные правопорядки государств-членов должны включать специальные меры по обеспечению выполнения права ЕС, иными словами, соблюдать принцип лояльности. В ст. 4 Договора о Европейском союзе указано, что «Союз и государства-члены проявляют взаимное уважение и содействуют друг другу в выполнении задач, вытекающих из Договоров. Государства-члены предпринимают любые меры общего или специального характера, которые способны обеспечить исполнение обязанностей, вытекающих из Договоров или проистекающих из актов институтов Союза. Государства-члены создают благоприятные условия для выполнения Союзом его задач и воздерживаются от любых мер, способных поставить под угрозу достижение целей Союза» ${ }^{28}$.

В отношении норм права ЕС, обладающих прямым действием, государства-члены не могут принимать любые акты с целью реализации

290 их положений. Они также обязаны воздерживаться от опубликования постановлений институтов ЕС, содержащие нормы прямого действия (например, регламентов) в своих сборниках законодательных актов. Реализация права EC на территории государств-членов осуществляется с

${ }^{25}$ Marshall v. Southampton and South-West Hampshire Area Health Authority. Case 152/84. [1986] ECR 727.

${ }^{26}$ Acciaierie San Michele Spa (In Liquidation) v High Authority Of The ECSC ECJ. Cases 9 and 58/65. [1967] ECR 1.

${ }^{27}$ Интернационализация конституционного права : современные тенденции / под ред. Н. В. Варламовой и Т. А. Васильевой. М., 2017. С. 157.

${ }_{28}$ Договор о Европейском союзе. URL: https://eulaw.ru/treaties/teu/ (дата обращения: 01.02.2020). 


\section{Международное и европейское право}

помощью мер со стороны институтов и органов Союза, а также правотворческой и правоприменительной деятельности государств-членов. В рамках ЕС и в государствах-членах функционирует целая система органов, которые занимаются реализацией права ЕС. Между этими органами происходит распределение компетенции по реализации норм права Союза. Ответственность за деятельность органов, реализующих право ЕС, несут Союз и государства-члены в пределах собственных полномочий, так как для Европейского союза как наднационального образования характерно отсутствие своих «региональных» или «местных» органов власти, обеспечивающих исполнение их решений на территории государств-членов ${ }^{29}$.

Некоторые государства-члены приняли законодательные акты, которые обеспечивают общую инкорпорацию права ЕС во внутреннее законодательство. Однако подавляющее большинство государств-членов для обеспечения правовой основы действия права ЕC на своей территории внесло изменения в национальные конституции. Это было сделано ими путем включения в них соответствующих положений о передаче полномочий, примате и прямом действии права ЕС.

Например, вступление Ирландии в Европейские сообщества требовало обязательного проведения референдума: поскольку обязательства, вытекающие из учредительных документов Сообществ, противоречили нормам Конституции Республики. Так, ст. 15.2.1 Конституции наделяет парламент монополией на законотворчество: «...ни одна другая законодательная власть не имеет права принимать законодательные акты для государства». Сходные нормы существовали и в отношении судопроизводства: «Решения Верховного Суда должны быть окончательными и решающими» (ст. 34.4.6 Конституции) ${ }^{30}$. Указанные статьи Конституции были несовместимы с членством Ирландии в Сообществах. Однако в 1972 г. было решено не изменять эти и другие статьи Конституции, а вместо этого принять одну обобщающую поправку, добавив в ст. 29.4 п. 3, позволяющий стране вступить в Сообщества. Положения ст. 46.2 Конституции Ирландии предусматривают, что для внесения изменений в Конституцию требуется одобрение граждан на референдуме ${ }^{31}$.

Кроме того, механизм имплементации норм права ЕС в правовой системе страны был оформлен парламентским «Актом о Европейских сообществах» от 16 декабря 1972 г. ${ }^{32}$ Акт законодательного характера был необходим для конкретизации порядка применения права ЕС в рамках ирландской правовой системы. Он стал «двигателем» имплементации в

${ }^{29}$ См.: Варлалова Н. В. Проблемы институционализации наднационального уровня осуществления публично-властных полномочий // Интернационализация конституционного права в условиях глобализации. Труды Института государства и права Российской академии наук. М., 2014. № 6. С. 13.

${ }^{30}$ Constitution of Ireland. URL: https://www.gov.ie/en/publication/d5bd8c-constitution-of-ireland/ (дата обращения: 01.02.2020).

${ }^{31}$ Ibid.

${ }^{32}$ The European Communities Act 1972 // Acts of the Oireachtas. № 27/1972. 


\section{Вестник ВГУ. Серия: Право}

право Ирландии документов, принятых институтами Европейских сообществ / союза ${ }^{33}$.

В Ирландии Акт о Европейских сообществах 1972 г. наделяет полномочиями министров правительства страны имплементировать директивы органов ЕС посредством издания постановлений в соответствии со ст. 3 указанного акта. Большинство директив было имплементировано в ирландском праве таким образом ${ }^{34}$. Конституционность таких норм Акта 1972 г. была подтверждена в 1993 г. решением Верховного суда по делу Meagher v Minister for Agriculture and Food ${ }^{35}$. Верховный суд подтвердил фундаментальное условие членства государств в ЕС - верховенство коммунитарного права над внутренним правом стран-членов. В решении по делу Meagher было также практически полностью процитировано решение Суда ЕС по делу Francovich v Italian Republic ${ }^{36}$.

В целом особая юридическая природа права ЕС приобретает исключительное значение в характеристике вопросов его соотношения с национальными правовыми системами государств-членов. Вопрос о том, как право Европейского союза взаимодействует с национальным правом государств-членов и каковы последствия такого взаимодействия, безусловно, связано, среди прочего, с реализацией основных принципов права ЕС.

Основополагающие конституционные особенности права Союза не всегда можно найти в учредительных договорах данного интеграционного объединения, поскольку они берут свое начало в прецедентном праве EC. Вышеизложенное обсуждение в отношении характера отношений между национальным правом и правом Союза должно рассматриваться в свете чрезвычайно широкого регулятивного воздействия ЕС. Сфера действия права ЕС все более расширяется, охватывая не только такие вопросы, как налогообложение, таможенное регулирование, конкурент-

$\sim$ ное право, финансовые услуги, корпоративная сфера, трудовые отношения, защита прав потребителей и договорное право, иммиграционные и уголовные нормы. Фактически можно утверждать, что в национальном законодательстве практически нет сферы действия, которая не была бы затронута регулирующей деятельностью Союза. Иными словами, большая часть положений, применяемых на национальном уровне, вытекает из законодательства ЕС. Этот расширяющийся процесс европеизации привел к увеличению количества правовых источников и быстрой модернизации всего массива национального законодательства в различных областях. В любом случае от эффективности деятельности механизма ре-

${ }^{33}$ См.: Галушко Д. В. Правовые и институционные основы взаимодействия Ирландии и Европейского союза. Воронеж, 2008. С. 88.

${ }^{34}$ См.: Галушко Д. В. Особенности имплементации «вторичного» права Европейских сообществ (союза) в Ирландии // Международное публичное и частное право. 2007. № 3 (36). С. 37.

${ }^{35}$ Meagher v Minister for Agriculture and Food. [1994] 1 IR 329.

${ }^{36}$ Andrea Francovich and Danila Bonifaci and others v Italian Republic. References for a preliminary ruling: Pretura di Vicenza and Pretura di Bassano del Grappa - Italy. Joined cases C-6/90 and C-9/90. [1991] ECR I-05357. 


\section{Международное и европейское право}

ализации норм права ЕС во внутренних правопорядках государств-членов будут зависеть темпы развития и углубления интеграции в рамках Европейского союза.

Воронежский государственный университет

Галушко Д. В., кандидат юридических наук, доцент кафедрь международного и евразийского права

E-mail: galushkodv@gmail.com
Voronezh State University

Galushko D. V., Candidate of Legal Sciences, Associate Professor of the International and Eurasian Law Department

E-mail: galushkodv@gmail.com 